\title{
REVIEW
}

\section{Job strain and risk of obesity: systematic review and meta-analysis of cohort studies}

\author{
M Kivimäki ${ }^{1,2}$, A Singh-Manoux ${ }^{1,3}$, S Nyberg $^{4}$, M Jokela ${ }^{5}$ and M Virtanen ${ }^{4}$
}

Job strain, the most widely used indicator of work stress, is a risk factor for obesity-related disorders such as cardiovascular disease and type 2 diabetes. However, the extent to which job strain is related to the development of obesity itself has not been systematically evaluated. We carried out a systematic review (PubMed and Embase until May 2014) and meta-analysis of cohort studies to address this issue. Eight studies that fulfilled inclusion criteria showed no overall association between job strain and the risk of weight gain (pooled odds ratio for job strain compared with no job strain 1.04, 95\% confidence interval (Cl) 0.99-1.09, $\left.N_{\text {Total }}=18240\right)$ or becoming obese $\left(1.00,95 \% \mathrm{Cl} 0.89-1.13, N_{\text {Total }}=42222\right)$. In addition, a reduction in job strain over time was not associated with lower obesity risk $\left(1.13,95 \% \mathrm{Cl} 0.90-1.41, N_{\text {Total }}=6507\right)$. These longitudinal findings do not support the hypothesis that job strain is an important risk factor for obesity or a promising target for obesity prevention.

International Journal of Obesity (2015) 39, 1597-1600; doi:10.1038/ijo.2015.103

\section{INTRODUCTION}

The obesity epidemic is a major public health challenge. ${ }^{1}$ Both physical inactivity and an unhealthy diet increase the risk of obesity, but interventions targeting these factors have not been successful in preventing or reversing obesity at the population level. ${ }^{2-4}$ Effective prevention, therefore, needs a strategy based on the importance of a wider range of risk factors.

Job strain, the most widely studied work-related psychosocial stressor, is seen as influencing the risk of obesity. ${ }^{5,6}$ In agreement with this, meta-analyses have linked job strain to obesity in crosssectional ${ }^{7}$ and to an increased risk of obesity-related disorders, such as type 2 diabetes, coronary heart disease and stroke in longitudinal studies. ${ }^{8-10}$ However, the extent to which job strain is related to weight gain and the development of obesity itself is poorly understood, ${ }^{11-14}$ because quantitative reviews to confirm or refute these longitudinal associations are lacking. Similarly, it remains unclear whether a reduction in job strain is likely to reduce obesity risk and, thus, be a potentially useful target for obesity prevention.

Here we seek to address these questions by performing a systematic review and meta-analysis of prospective studies on the associations between job strain, change in job strain and the risk of weight gain and obesity.

\section{METHODS}

Data sources and searches

Following the PRISMA guidelines, ${ }^{15}$ we performed a systematic search of the literature using 'all fields' in PubMed and Embase on 21 August 2014; search terms: (job strain, job stress, work stress, job demands, job control, workload, job psychosocial or work psychosocial) and (body mass index, overweight, obesity or BMI).
We also examined the reference lists of major reviews in the field ${ }^{11-14}$ as well as those of the eligible publications, and performed a cited-reference search of these using the Institute of Scientific Information Web of Science (2014). Two authors (Kivimäki, Virtanen) independently reviewed titles and abstracts to retrieve potentially relevant studies and full articles were reviewed to evaluate whether they met the inclusion criteria.

\section{Inclusion criteria}

We included studies that meet the following eligibility criteria: published in English; prospective design (cohort study) with individual level exposure and outcome data; examined the effect of job strain, as defined in the theoretical model by Karasek; ${ }^{5}$ weight gain or development of obesity as an outcome; and reported either estimates of relative risk, odds ratios or hazard ratios with $95 \%$ confidence intervals $(\mathrm{Cls})$, or provided sufficient results to calculate these estimates.

\section{Data synthesis and statistical analysis}

Meta-analysis was used to combine the estimates from the studies reported as odds ratios or relative risk. Associations of job strain with weight gain (yes/no) and becoming obese (yes/no) were analyzed separately. The basic model was adjusted for age, sex and socioeconomic status (SES) as covariates. SES is associated with job strain (the highest prevalence of job strain is typically in low-SES jobs) and multiple health outcomes, including obesity (overweight and obesity are most common in low-SES groups). ${ }^{16,17}$ We also examined associations of increase and reduction in job strain and change in weight or obesity risk in studies where relevant data were available. We examined heterogeneity of study-specific estimates using the $I^{2}$ statistic; as it was low ( $\leqslant 48 \%$ in all analyses), we used fixed effects analysis

\footnotetext{
${ }^{1}$ Department of Epidemiology and Public Health, University College London, London, UK; ${ }^{2}$ Department of Public Health, Faculty of Medicine, University of Helsinki, Helsinki, Finland; ${ }^{3}$ Inserm, Centre for Research in Epidemiology and Population Health, Hôpital Paul Brousse, Villejuif, France; ${ }^{4}$ Finnish Institute of Occupational Health, Helsinki, Finland and ${ }^{5}$ Institute of Behavioral Sciences, University of Helsinki, Helsinki, Finland. Correspondence: Professor M Kivimäki, Department of Epidemiology and Public Health, University College London, 1-19 Torrington Place, London WC1E 6BT, UK.

E-mail: m.kivimaki@ucl.ac.uk

Received 4 February 2015; revised 17 April 2015; accepted 1 May 2015; accepted article preview online 4 June 2015 ; advance online publication, 30 June 2015
} 
(for comparison, results from random effects meta-analysis are reported in Supplementary Appendix). All statistical analyses were performed using Stata (MP version 11.2, College Station, TX, USA).

\section{RESULTS}

Literature search of published studies

Initial search of PubMed and Embase retrieved 3579 results, but only eight cohort studies from five papers fulfilled inclusion criteria (for details, see Supplementary Appendix). ${ }^{7,18-21}$ By hand searching through reference lists within those studies, one additional study was identified. ${ }^{22}$ After removing one article reporting results from the same cohort, ${ }^{21}$ eight independent studies from five papers were included in the meta-analysis. ${ }^{7,18-20,22}$

Meta-analysis of prospective cohort studies

Four cohort studies contributed to the analysis of obesity ${ }^{7}$ but none reported a significant association between job strain and the risk of becoming obese (Figure 1). In fixed-effect meta-analysis, the minimally adjusted pooled odds ratio for job strain compared with no job strain was $1.00(95 \% \mathrm{Cl} 0.89-1.13$, total $N=42222)$ with little heterogeneity in study-specific estimates $\left(I^{2}=18.3 \%\right.$, $P=0.30)^{7}$ Similarly, the pooled odds ratio did not show an association between job strain and gaining weight $(1.04(95 \% \mathrm{Cl}$ $0.99-1.09$, total $\left.N=18,240, I^{2}=48.4 \%, P=0.072\right){ }^{18-20,22}$ although in two studies an association was observed in women $(1.80,95 \%$ $\mathrm{Cl} 1.00-3.24$ in Shields et al. ${ }^{20}$ and $1.25,95 \%$ Cl 1.05-1.49 in Roos et al.). ${ }^{22}$ The random effects modeling produced similar results. Moreover, the findings were not dependent on the length of follow-up time (data tabulated in the Supplementary Appendix).

None of these studies examined whether the association between job strain and risk of obesity or weight gain followed a dose-response gradient (that is, whether a greater exposure to job strain was associated with greater increases in obesity risk).
Change in job strain in relation to change in obesity risk

Individuals who had job strain at baseline but not at follow-up did not have a lower risk of becoming obese compared with those who had job strain both at baseline and follow-up (pooled odds ratio $1.13,95 \% \mathrm{Cl} 0.90-1.41$, total $N=6507) .{ }^{7}$ However, an increase in job strain was linked to increased obesity risk among initially job strain-free individuals, when compared with those with no persistent job strain $(1.18,95 \% \mathrm{Cl} 1.02-1.36$, total $N=35715){ }^{7}$

\section{DISCUSSION}

In the studies identified from the literature, there was no overall association between job strain and risk of weight gain or obesity. An increase in job strain was linked to simultaneous increased obesity risk among initially job strain-free individuals, although a reduction in job strain, compared with persistent job strain, was not associated with reduced odds of obesity. These longitudinal findings on job strain and obesity are not consistent with the hypothesis that job strain is an important risk factor for obesity.

In prospective observational studies, demonstration of a temporal sequence in the exposure-outcome association supports the view that the exposure is a putative risk factor. Such evidence was not obtained for job strain as there was no overall association with weight gain and obesity. In the only statistically significant longitudinal observation, an increase in job strain between the baseline and follow-up was associated with a simultaneous increase in obesity. ${ }^{7}$ However, these contemporaneous changes did not allow us to determine whether the change in job strain preceded the change in obesity or whether weight gain increased subsequent risk of experiencing job strain.

Further considerations in determining whether an exposure is a genuine risk factor involve evidence of a graded dose-response association between an exposure and an outcome. ${ }^{23}$ Such pattern strengthens the evidence, although lack of dose response is not
N

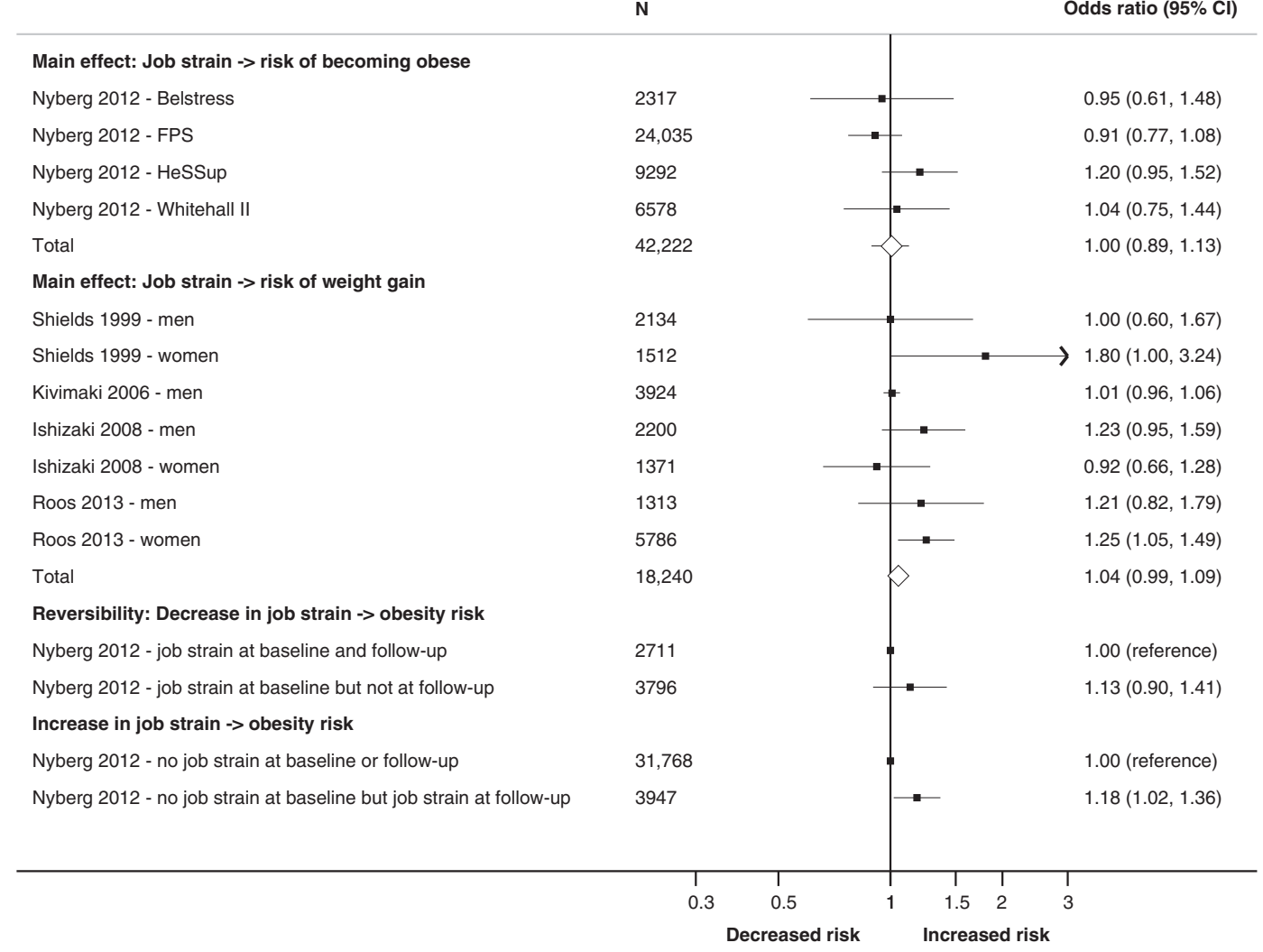

Figure 1. Meta-analysis of cohort studies on associations of job strain and change in job strain with risk of obesity and weight gain. 
evidence against potential causal association because threshold effects are also possible. ${ }^{23}$ Dose response was examined only in one prospective study but that study did not fulfill the inclusion criteria for this meta-analysis. ${ }^{21}$ As the study used a modified iso-strain measure that includes social support in addition to job demands and job control, it is unclear whether the observed dose-response gradient also characterizes the job strain-obesity association. Cross-sectional data on job strain support this possibility but results from cross-sectional studies are known to be subject to reverse causation bias. $^{7}$

The job strain model was originally developed for modeling psychosocial factors that affect mental health. ${ }^{5}$ Such problems, depression in particular, are by definition associated with an increase or decrease in appetite leading to weight gain in some patients and weight loss in others. It may therefore be hypothesized that job strain leads, directly or through increased mental health problems, to weight loss in some individuals, thus masking the overall association between job strain and weight gain. ${ }^{18}$ However, the evidence to support this possibility is inconsistent. In one study, job strain was associated with weight loss in men with low body mass index and weight gain in overweight and obese men, but no such weight changes were observed in women. ${ }^{18}$ Therefore, there is need for further research to determine the potential individual differences in response patterns when facing job strain and to examine the proportion of persons with increased unhealthy eating under stress, thus leading to an increased risk of gaining weight; those who lose appetite in such circumstances and are at an increased risk of weight loss; and those who remain unaffected in terms of eating behaviors, physical activity and the metabolic rate. However, given the lack of an association between job strain and risk of obesity in the total population, the first group is likely to be small.

Our meta-analysis benefits from focusing both on the presence of and change in job strain in relation to obesity risk. A drawback is that the assessment of job strain varied between the studies included in the analysis, which suggests that despite the concept of job strain concept being proposed already in 1979, there is still no general agreement on the best measure. Multiple and changing job strain definitions increase uncertainty in the results, making it impossible to determine whether the use of an alternative definition would have led to a different conclusion. Our evidence base of up to 44000 individuals mainly consists of European studies and is much smaller than those reported in meta-analyses of job strain, coronary heart disease ${ }^{9}$ and type 2 diabetes. $^{8}$ The generalizability of our findings should therefore be interpreted with caution, particularly as the statistical power was insufficient to detect small effects. Last, our meta-analysis was focused on one major work stressor, job strain, although other stressors (for example, effort-reward imbalance at work and caregiving burden in private life) might also be relevant. As job strain represents only a part of potential psychosocial stresses, we cannot exclude the possibility that prevention of stress in general, especially in combination with lifestyle interventions, could favorably affect weight management.

In conclusion, using prospective data, we show no consistent association between job strain and the development of obesity or weight gain. These findings suggest that job strain may not be an important risk factor for obesity and that job strain interventions alone, although improving psychological wellbeing at work, are not likely to alleviate the obesity epidemic, even in the working populations. However, because of the limitations in the published studies, we cannot exclude the possibility that there are subgroups of individuals who gain weight under job strain, although the null finding in the total data suggests that they represent the minority.

\section{DISCLAIMER}

The funders had no role in the study design; in the collection, analysis and interpretation of data; in writing of the report; or in the decision to submit the paper for publication.

\section{CONFLICT OF INTEREST}

The authors declare no conflict of interest.

\section{ACKNOWLEDGEMENTS}

MK is supported by the Medical Research Council (K013351), NordForsk, the Nordic Council of Ministers (grant 75021), the National Heart, Lung and Blood Institute (HL36310), the National Institute of Aging (AG034454), the Academy of Finland, and an ESRC professorial fellowship. MV is supported by the Academy of Finland. We thank Mr Kimmo Kallio for help in retrieving the literature.

\section{REFERENCES}

$1 \mathrm{Ng} \mathrm{M}$, Fleming T, Robinson M, Thomson B, Graetz N, Margono C et al. Global, regional, and national prevalence of overweight and obesity in children and adults during 1980-2013: a systematic analysis for the Global Burden of Disease Study 2013. Lancet 2014; 384: 766-781.

2 Hebden L, Chey T, Allman-Farinelli M. Lifestyle intervention for preventing weight gain in young adults: a systematic review and meta-analysis of RCTs. Obesity Rev 2012; 13: 692-710.

3 Liao Y, Liao J, Durand CP, Dunton GF. Which type of sedentary behaviour intervention is more effective at reducing body mass index in children? A metaanalytic review. Obesity Rev 2014; 15: 159-168.

4 Johansson K, Neovius M, Hemmingsson E. Effects of anti-obesity drugs, diet, and exercise on weight-loss maintenance after a very-low-calorie diet or low-calorie diet: a systematic review and meta-analysis of randomized controlled trials. Am J Clin Nutr 2014; 99: 14-23.

5 Karasek RA. Job demands, job decision latitude and mental strain: implications for job redesign. Admin Sci Quart 1979; 24: 285-307.

6 Block JP, He Y, Zaslavsky AM, Ding L, Ayanian JZ. Psychosocial stress and change in weight among US adults. Am J Epidemiol 2009; 170: 181-192.

7 Nyberg ST, Heikkila K, Fransson El, Alfredsson L, De Bacquer D, Bjorner JB et al. Job strain in relation to body mass index: pooled analysis of 160000 adults from 13 cohort studies. J Intern Med 2012; 272: 65-73.

8 Nyberg ST, Fransson El, Heikkilä K, Ahola K, Alfredsson L, Bjorner JB et al. Job strain as a risk factor for type 2 diabetes: a pooled analysis of 124808 men and women. Diabetes Care 2014; 37: 2268-2275.

9 Kivimaki M, Nyberg ST, Batty GD, Fransson El, Heikkilä K, Alfredsson L et al. Job strain as a risk factor for coronary heart disease: a collaborative meta-analysis of individual participant data. Lancet 2012; 380: 1491-1497.

10 Fransson El, Nyberg ST, Heikkilä K, Alfredsson L, Bjorner JB, Borritz M et al. Job strain and the risk of stroke: An individual-participant data meta-analysis. Stroke 2015; 46: 557-559.

11 Wardle J, Chida Y, Gibson EL, Whitaker KL, Steptoe A. Stress and adiposity: a metaanalysis of longitudinal studies. Obesity 2011; 19: 771-778.

12 Solovieva S, Lallukka T, Virtanen M, Viikari-Juntura E. Psychosocial factors at work, long work hours, and obesity: a systematic review. Scand J Work Environ Health 2013; 39: 241-258.

13 Overgaard D, Gyntelberg F, Heitmann BL. Psychological workload and body weight: is there an association? A review of the literature. Occup Med 2004; 54: 35-41.

14 Siegrist J, Rodel A. Work stress and health risk behavior. Scand J Work Environ Health 2006; 32: 473-481.

15 Moher D, Liberati A, Tetzlaff J, Altman DG. Preferred reporting items for systematic reviews and meta-analyses: the PRISMA statement. PLoS Med 2009; 6: e1000097.

16 Bosma H, Peter R, Siegrist J, Marmot M. Two alternative job stress models and the risk of coronary heart disease. Am J Public Health 1998; 88: 68-74.

17 Mackenbach JP, Stirbu I, Roskam AJ, Schaap MM, Menvielle G, Leinsalu M et al. Socioeconomic inequalities in health in 22 European countries. N Engl J Med 2008; 358: $2468-2481$.

18 Kivimäki M, Head J, Ferrie JE, Shipley MJ, Brunner E, Vahtera J et al. Work stress, weight gain and weight loss: evidence for bidirectional effects of job strain on body mass index in the Whitehall II study. Int J Obes 2006; 30: 982-987.

19 Ishizaki M, Nakagawa H, Morikawa Y, Honda R, Yamada Y, Kawakami N. Influence of job strain on changes in body mass index and waist circumference--6-year longitudinal study. Scand J Work Environ Health 2008; 34: 288-296.

20 Shields M. Long working hours and health. Health Rep 1999; 11: 33-48. 
21 Brunner EJ, Chandola T, Marmot MG. Prospective effect of job strain on general and central obesity in the Whitehall II Study. Am J Epidemiol 2007; 165: 828-837.

22 Roos E, Lallukka T, Rahkonen O, Lahelma E, Laaksonen M. Working conditions and major weight gain-a prospective cohort study. Arch Environ Occup Health 2013, 68: $166-172$.

23 Bradford Hill A. The environment and disease: association or causation? Proc Roy Soc Med 1965; 58: 295-300. (i) This work is licensed under a Creative Commons Attribution 4.0 International License. The images or other third party material in this article are included in the article's Creative Commons license, unless indicated otherwise in the credit line; if the material is not included under the Creative Commons license, users will need to obtain permission from the license holder to reproduce the material. To view a copy of this license, visit http://creativecommons.org/licenses/ by/4.0/

Supplementary Information accompanies this paper on International Journal of Obesity website (http://www.nature.com/ijo) 